\title{
OS SENTIMENTOS DO PACIENTE COM TRANSTORNO DE PERSONALIDADE BORDERLINE: A ANGÚSTIA, AUTOACEITAÇÃO E SEU RELACIONAMENTO COM A SOCIEDADE \\ Lucas Tadeu Rezende ${ }^{1}$
}

Resumo: A caracterização do Transtorno de personalidade com instabilidade emocional (Borderline) se dá por um padrão de impulsividade e instabilidade quanto a relacionamentos interpessoais, à autoimagem e aos afetos. Nos arranjos limítrofes o Ego em formação consegue ultrapassar o momento em que as frustrações da primeira idade teriam podido operar fixações pré-psicóticas tenazes e desagradáveis, não regredindo a essas fixações. Entretanto no momento que se da a evolução edipiana normal esses sujeitos sofreram um trauma psíquico importante. As exigências pulsionais precisam ser devidamente reprimidas para que exista uma vida socialmente aceitável. Acaba por existir um emprego incorreto da libido que pode ocasionar maiores complicações no estado psicopatológico do paciente. As exigências pulsionais são um grande desafio para o paciente Borderline, pois sua inadequação na leitura correta de seus sentimentos unida a sua impulsividade acarretam breves surtos que acabam por prejudicar a busca por um prognóstico positivo.

Palavras-chave: Transtorno de personalidade Borderline; Transtorno de personalidade limítrofe; Psicanálise e Borderline; Sociedade e o Borderline.

\footnotetext{
${ }^{1}$ Casa da Enfermagem, R: Anésia Nunes Matarazzo, 113 - Vila Rubi - São José dos Campos /SP, Brasil. E-mail: lucas.nacional@hotmail.com.
} 